\title{
Mercadotecnia y sociedad de consumo
}

\author{
Marketing and Consumer society
}

Alejandra Vega Barrios a

\begin{abstract}
:
The book Marketing and Consumer Society, initiates with various aspects related to consumption, and marketing studies from perspective of consumption is presented, in such it is analysed how market strategies influence's society. Since the definition of Marketing under the different approaches, between economic, cultural and social as well as consumption and social responsibility, price as a variable that generates value, or if selling is marketing purpose, as well as successful cases in the image that is intended to show but having internal errors that contradict the campaigns and new technologies to try to understand what is observed by the customers' eyes in advertising and packaging, to conclude with unbridled consumption by the social context in which the most vulnerable consumers and workers develop.
\end{abstract}

Keywords:

Marketing, strategies, consumption

\section{Resumen:}

El libro Mercadotecnia y Sociedad de Consumo, inicia diversos aspectos relacionados con el consumo, por lo que se presenta el estudio de la mercadotecnia desde la perspectiva del consumo, de tal forma que se analiza de qué forma influyen las estrategias mercadológicas en la sociedad actual. Desde la definición de Mercadotecnia bajo los diferentes enfoques, entre lo económico, cultural y social así como el consumo y la responsabilidad social, mostrando fijación de precio como una variable que genera el intercambio de valor, o si es realmente vender el fin de la mercadotecnia, así como casos exitosos en la imagen que se pretende mostrar pero teniendo errores de manera interna que contradicen las campañas y las nuevas tecnologías para tratar de entender que es lo que observan los ojos de los clientes en la publicidad y los empaques, para concluir con el consumo desenfrenado por el contexto social en donde se desenvuelven los consumidores y trabajadores más vulnerables.

\section{Palabras Clave:}

Mercadotecnia, Estrategias, Consumo

\section{Introducción}

El libro se encuentra estructurado en nueve capítulos, que muestran el consumo y la mercadotecnia desde distintas perspectivas y sugieren al lector identificar desde los conceptos y teorías hasta la aplicación de los mismos.

Los capítulos son: I. El consumo como objeto discursivo desde las ciencias sociales. II. Cultura y Consumo, una reflexión crítica. III Un enfoque social de la mercadotecnia. IV. Hablando de Mercadeo ¿Ángel o demonio? V. La fijación del precio en un entorno competitivo, VI. Mercadotecnia y Responsabilidad Social ¿Socios o antagonistas?, VII Luces y sombras en torno a la responsabilidad social de las empresas: Caso $\mathrm{Mc}$ Donald's. VIII. Análisis de los movimientos oculares del consumidor: Aplicaciones contemporáneas al diseño y finalmente, el último capítulo, denominado Consumo y desenfreno: Una aproximación etnográfica sobre excesos y economías ilícitas en la frontera sur de México.

En el primer capítulo se analiza el concepto de consumo desde el ámbito de las ciencias sociales, partiendo de las diversas teorías, escuelas de pensamiento y tradiciones ideológicas, de tal forma que se estudia el consumo a partir la economía clásica, como energía social, a través de la filosofía del dinero, como valor de uso, esfera no discursiva, manifiesto de la mercancía y el dandy, Por otra parte, como consumo conspicuo, y la crítica al consumo.

El capítulo segundo, nos habla del concepto de cultura como un fenómeno colectivo; siendo el resultado de los primeros años de convivencia humana, forma 
permanente y por otra parte el fenómeno de consumo, donde se le ha acusado de modificar los valores de una sociedad traducidos al consumismo, llevándonos a la influencia de la cultura en el consumo, hasta el consumo como una actividad cultural, para concluir que la cultura influye en el derroche y a la vez es una expresión de la cultura prevaleciente en el seno de cada grupo social, por lo que a manera de reflexión se establece que la actividad de compra tiene influencia a partir de la cultura que se toma desde el núcleo familiar.

En el tercer capítulo, se habla del enfoque social de la mercadotecnia, la cual ha sido considerada como un instrumento de manipulación, de intoxicación y hasta de alineación de los consumidores, así mismo se ha acusado a esta disciplina por el daño a los consumidores mediante estrategias de precios, exageración en las características de los productos, rebajas de artículos agotados, ventas de alta presión, así como la obsolescencia planeada y el mal servicio a los clientes, considerando la disciplina de forma negativa pues se fomenta el consumismo, por lo que se han realizado diversas acciones entre ellas la Responsabilidad Social Corporativa (RSE), cuidado y preservación ambiental, calidad de vida, desarrollo del capital humano y la ética empresarial, entre otros, por lo que las necesidades sociales deben analizarse siendo las organizaciones de los diversos sectores quienes buscan satisfacerlas en diversas fuentes como en la empresa pública, mediante el poder político, en la empresa privada por poder económico o financiero y en el organismo social través de la cooperación de los miembros.

El capítulo cuarto, revisa la cultura del marketing, estableciendo que la disciplina y las dinámicas del mercadeo no son estáticas, dado que se encuentran inmersas en la cultura que las produce, donde la disciplina sigue siendo acusada de generar discriminación, engañar, manipular y hasta de ir en contra de la libre expresión, por lo que se estudia la ética del mercadeo donde se pueden identificar tres formas en que el marketing ha sido evaluado, por una parte el utilitarismo, argumentando que la mercadotecnia facilita la división del trabajo, por otra parte se evalúa la deontología que relaciona el marketing de productos que pueden causar algún daño o con formas no éticas de promocionar un producto, por lo que se vislumbra la ética de la virtud que refiere a las intenciones del mercadólogo en la construcción y el eje de campaña, así mismo se reconoce la emoción del consumo, ya que la realidad creada por las campañas de marketing y la contexto propio del individuo, dando como resultado la compra, además de la apropiación y la recreación del mensaje mediante el uso de las emociones, de tal forma que el consumo también genera comunidad, por lo que se concluye que el marketing es consumo de ideas y de objetos a la vez que es una situación generada y generadora, siendo la comunicación entre individuos con el fin de obtener un beneficio.

El quinto capítulo define la fijación del precio en un entorno competitivo, iniciando desde la definición de la variable de marketing precio, la cual de acuerdo a Lerma (2008, p.159) el precio es un valor monetario que se cobra por una enajenación de un bien o servicio. Siendo que el precio ha sido el principal factor que influye en la decisión de los compradores. Es por ello que se estudian los factores que intervienen en la fijación de los precios, dividiéndolos en dos tipos, los factores internos que establecen los objetivos del marketing, la estrategia de la mezcla de mercadotecnia, los costos y las consideraciones organizacionales, mientras que los factores externos, se vislumbra la naturaleza del mercado, la demanda, la elasticidad de los productos y los precios, la competencia, y algunos factores del entorno como la economía, el gobierno y los intermediarios.

El siguiente apartado, denominado Mercadotecnia y Responsabilidad Social Empresarial: ¿Socios 0 Antagonistas?, menciona como principal hipótesis si es que el propósito fundamental de la mercadotecnia es vender más o que es "crear" las necesidades del cliente, haciendo la revisión de la literatura sobre mercadotecnia, señalando primeramente en la definición como el conjunto de actividades ideadas para generar y facilitar el intercambio con la intención de satisfacer necesidades, deseos humanos o de organizaciones, para las que deben intervenir dos o más personas $u$ organizaciones con deseos que requieran satisfacer puesto que para una persona autosuficiente no hay necesidad de intercambio. Y por otra parte en la investigación de la Responsabilidad social empresarial (RSE), como la contribución activa y voluntaria de las empresas en el mejoramiento social, económico y ambiental. De tal suerte que el ser socialmente responsable no significa solamente cumplir plenamente las obligaciones jurídicas, sino ir más allá, invirtiendo en el capital humano, en la preservación del entorno y las relaciones con los interlocutores. [1]

Por otra parte, se menciona que la RSE es la conciencia del comportamiento y la acción de la mejora continua, consistente que hace posible a la empresa ser más competitiva, cumpliendo con las expectativas de todos los participantes en lo particular y de la sociedad en lo general, respetando la dignidad de la persona y de las comunidades en las que opera, así como en su entorno.

Por lo que se requiere rescatar el verdadero significado de la mercadotecnia, el cual va más allá de ser solamente una herramienta de venta y de servicio para llegar a los 
clientes. La mercadotecnia puede ayudar a las empresas a lograr la confianza de los clientes por medio del trato ético en el ofrecimiento de sus productos y servicios, además de promover acciones de vinculación con el desarrollo de la sociedad, además de fomentar el cuidado ambiental; Además puede emplearse mercadotecnia hacia adentro de las organizaciones, estimulando relaciones adecuadas entre la empresa y sus trabajadores, mejorando su calidad de vida laboral.

Así mismo, se examina un caso sobre McDonald's, empresa de comida rápida desde hace 64 años y con una participación del $20 \%$ del mercado estadounidense, a la cual se le acusa de promover el consumo de alimentos ricos en grasas y sal, a pesar de contar con un programa para realizar acciones de mercadotecnia y responsabilidad social integradas. El cual aporta ayuda en los sectores de Educación, Deporte, Salud, Niñez, Adultos Mayores, Personas con capacidades diferentes, Concientización ciudadana, programas derivados de la Fundación Infantil Ronald McDonald se ha visto envuelto en diversas problemáticas, con sus trabajadores quienes acotan un término McJob, definido por un autor canadiense, Douglas Coupland como "un trabajo poco remunerado, de poco prestigio, poca dignidad y pocos beneficios, que no ofrece ningún futuro" por lo que se puede entender las inconsistencias de la empresa en cuanto a responsabilidad social.

En el octavo capítulo, realiza el análisis de los movimientos oculares del consumidor: Aplicaciones contemporáneas al diseño, explicando brevemente sobre las tecnologías de eye tracking (rastreo visual) y sus aplicaciones en el diseño, basándose en sensores de luz infrarroja que detectan los movimientos oculares de los individuos cuando estos interactúan con el espacio que los rodea, permitiendo evaluar el efecto de las imágenes sobre las personas.

Es interesante observar o encontrar las pautas de comportamiento visual de los consumidores frente a imágenes publicitarias o empaque de los diversos productos con lo que se puede medir el impacto.

Para concluir con esta reseña, el noveno capítulo habla sobre el consumo y desenfreno: Una aproximación etnográfica sobre excesos y economías ilícitas en la frontera sur de México, iniciando con la parte de consumo siendo una representación de un sistema de códigos y significados que opera en la mente de los individuos, como un proceso social donde todas las decisiones individuales son parte de un contexto que reúne variables de tipo ideológico, político y económico, definiendo el consumo desenfrenado con tres características:
1. Consumo excesivo y sin control en marcos de tiempo específico generalmente muy corto.

2. Consumo, en un contexto histórico, social y ecológico determinado y que está ligado a tipos de trabajo e industria en un sistema económico y,

3. Consumo desenfrenado, que contradice los valores de consumo generalmente aceptados por las clases dominantes en sociedades capitalistas, siendo el parte de grupos que viven en los márgenes de la sociedad y que por sus circunstancias sociales y económicas hacen que sus miembros decidan vivir por el momento y no realizar planeación para el futuro.[2]

Lo que nos aporta este texto, es la adecuación al consumo independientemente del momento en el que se realice, desde la cultura adquirida a través de familiares, grupos sociales o grupos de referencia como lo establecido por la mercadotecnia que comunica y estimula mediante precios, empaques e imágenes publicitarias la adquisición de bienes y servicios que compra y se autodestruye para pertenecer a la sociedad en la que se desenvuelve

\section{Referencias}

[1] D Sahuí Maldonado J, Mercadotecnia y Sociedad de Consumo. Editorial Dibs Fontamara 2010; 1era Edición. México

[2] Lerma A, Comercio y Marketing Internacional Cengage Learning; 2008: Cuarta Edición: .159 